\title{
Active cutaneous warming systems to prevent intraoperative hypothermia: a systematic review
}

\author{
Vanessa de Brito Poveda ${ }^{1}$ \\ Edson Zangiacomi Martinez ${ }^{2}$ \\ Cristina Maria Galvão ${ }^{3}$
}

\begin{abstract}
This study analyzed the evidence available in the literature concerning the effectiveness of different active cutaneous warming systems to prevent intraoperative hypothermia. This is a systematic review with primary studies found in the following databases: CINAHL, EMBASE, Cochrane Register of Controlled Trials and Medline. The sample comprised 23 randomized controlled trials. There is evidence in the literature indicating that the circulating water garment system is the most effective in maintaining patient body temperature. These results can support nurses in the decision-making process concerning the implementation of effective measures to maintain normothermia, though the decision of health services concerning which system to choose should also take into account its cost-benefit status given the cost related to the acquisition of such systems.
\end{abstract}

Descriptors: Hypothermia; Technology; Perioperative Nursing.

\footnotetext{
${ }^{1}$ RN, Ph.D. in Nursing, Full Professor, Faculdades Integradas Teresa D'Ávila, Lorena, SP, Brazil. E-mail: vbpoveda@yahoo.com.br.

2 Statistics, Free Lecturer, Associate Professor, Faculdade de Medicina de Ribeirão Preto, Universidade de São Paulo, SP, Brazil. E-mail: edson@fmrp.usp.br.

${ }^{3}$ RN, Ph.D. in Nursing, Full Professor, Escola de Enfermagem de Ribeirão Preto, Universidade de São Paulo, WHO Collaborating Centre for Nursing Research Development, SP, Brazil. E-mail: crisgalv@eerp.usp.br.
} 


\title{
Métodos ativos de aquecimento cutâneo para a prevenção de hipotermia no período intraoperatório: revisão sistemática
}

O estudo teve como objetivo analisar as evidências disponíveis na literatura sobre a efetividade dos diferentes métodos ativos de aquecimento cutâneo, para a prevenção de hipotermia no período intraoperatório. Para tal, a revisão sistemática foi empregada como método de revisão. A busca por estudos primários foi realizada nas bases de dados CINAHL, EMBASE, Cochrane Register of Controlled Trials e MEDLINE. A amostra da revisão foi composta por 23 ensaios clínicos randomizados controlados. Na literatura, há evidências que indicam que o sistema de circulação de água aquecida é o método mais efetivo à manutenção da temperatura corporal. Os resultados evidenciados podem subsidiar a tomada de decisão do enfermeiro na implementação de medidas efetivas para a manutenção da temperatura corporal. Recomenda-se, entretanto, que a escolha do sistema em cada serviço de saúde seja também baseada na análise custo/benefício, devido aos custos relativos à aquisição dos sistemas investigados.

Descritores: Hipotermia; Tecnologia; Enfermagem Perioperatória.

\section{Métodos activos de calentamiento cutáneo para la prevención de hipotermia en el período intraoperatorio: revisión sistemática}

\begin{abstract}
La finalidad del estudio fue analizar las evidencias disponibles en la literatura acerca de la efectividad de los diferentes métodos activos de calentamiento cutáneo para la prevención de hipotermia en el período intraoperatorio. Para esto, la revisión sistemática fue usada como método de revisión. La búsqueda de los estudios primarios fue efectuada en las bases de datos CINAHL, EMBASE, Cochrane Register of Controlled Trials y Medline. La muestra de la revisión abarcó 23 ensayos clínicos aleatorios controlados. La literatura ofrece evidencias que indican que el sistema de circulación de agua calentada es el método más efectivo en la manutención de la temperatura corporal. Los resultados evidenciados pueden subsidiar la toma de decisión del enfermero en la implementación de medidas efectivas para la manutención de la temperatura corporal. Sin embargo, considerando los costos de adquisición de los sistemas investigados, la elección del sistema en cada servicio de salud debería ser basada en el análisis de costo-beneficio.

Descriptores: Hipotermia; Tecnología; Enfermería Perioperatoria.
\end{abstract}

\section{Introduction}

The Association of PeriOperative Registered Nurses $^{(1)}$ recommends monitoring the body temperature of patients in the perioperative period because hypothermia is a common event among patients undergoing surgical anesthetic procedures. Hypothermia mainly occurs due to the action of anesthetics on the patient's thermoregulation and reduced metabolism, in addition to other factors that cause the individual to lose heat to the environment, such as the temperature of the surgical room and the opening of thoracic and abdominal cavities ${ }^{(2)}$.
Hypothermia can lead to complications, among which are cardiac arrhythmia, increased mortality, surgical site infection, coagulation abnormalities and abnormal platelet function, which increases patient blood loss, as well as thermo discomfort and also a more lengthy stay in the post anesthetic recovery room ${ }^{(3-4)}$. Therefore, the implementation of methods designed to maintain patient body temperature in the perioperative period is essential in order to prevent complications associated with hypothermia. 
During the surgical anesthetic procedure, approximately $90 \%$ of patient heat loss occurs from skin to environment. Cutaneous warming systems can be used to prevent such loss; these are divided into passive and active systems, while the use of (heated or unheated) cotton sheets and (tissue or adhesive) surgical fields are passive methods. There is current evidence that active cutaneous warming systems (heated air or water) are more effective in maintaining the patient's body temperature in the intraoperative. Up to the end of the 1990s, the forced-air warming system and circulating water mattress were the most used means in hospital practice ${ }^{(4-5)}$. New active cutaneous warming systems began to be used in the intraoperative period from 2000 on, which reinforces the need to acquire knowledge concerning the effectiveness and costs of new technologies intended to maintain patient normothermia.

The responsibility to adopt measures to prevent hypothermia in clinical practice rests with all the professionals involved in the patient's surgical care. Nurses, however, in addition to being responsible for planning and implementing interventions intended to improve quality of care, are involved in the decisionmaking process concerning the purchase of material and equipment in the context of health services.

\section{Objective}

This study analyzes evidence available in the literature concerning the effectiveness of the different active cutaneous warming systems used to prevent hypothermia during the intraoperative period.

\section{Method}

The steps followed in this systematic review included: the development of a protocol (research project), definition of a clinical question, search for primary studies, selection of studies, data collection, evaluation of the quality of studies and synthesis of evidence found(6-7).

\section{Guiding question and inclusion and exclusion criteria used to select primary studies}

The clinical question was: "What is the evidence available in the literature concerning the effectiveness of different active cutaneous warming systems to prevent hypothermia in the intraoperative period?"

Inclusion criteria were: randomized controlled trials testing active cutaneous warming systems in the intraoperative period (control group $=$ forcedair warming; experimental group = other active warming systems); published in English, Portuguese or Spanish from January 2000 to August 2010; sample composed of patients 18 years old or older; and who have underwent elective surgery. Exclusion criteria included: studies testing passive warming systems, using medication to prevent hypothermia, or testing pre-warming before administering anesthetics, or those studies in which hypothermia was induced in patients in the intraoperative.

\section{Search for primary studies}

Two authors (VBP and CMG) searched for the primary studies in the following databases: Cumulative Index to Nursing and Allied Health Literature (CINAHL), Medical Literature Analysis and Retrieval System on-line (Medline); Cochrane Central Register of Controlled Trials (CENTRAL, Clinical Trials) and EMBASE. A combination of controlled and non-controlled descriptors (key words) was used, based on each analyzed database (Figure 1).

\begin{tabular}{|l|l|l|}
\hline \multirow{2}{*}{ Data bases } & Controlled descriptors & $\begin{array}{c}\text { Non-controlled } \\
\text { descriptors }\end{array}$ \\
\hline \multirow{2}{*}{$\begin{array}{l}\text { MEDLINE and } \\
\text { COCHRANE }\end{array}$} & Hypothermia & Warming devices \\
\cline { 2 - 3 } & Body temperature changes & Warming system \\
\cline { 2 - 3 } CINAHL & Hypothermia & Active warming \\
\hline \multirow{3}{*}{ EMBASE } & Warming techniques & Warming devices \\
\cline { 2 - 3 } & Body temperature & Warming system \\
\hline \multirow{2}{*}{ Hypothermia } & Warming devices \\
\cline { 2 - 3 } & Warming & Warming system \\
\cline { 2 - 3 } & Body temperature & Active warming \\
\hline
\end{tabular}

Figure 1 - Databases selected for the search for primary studies, and controlled and non-controlled descriptors utilized

A total of 347 primary studies were identified in the selected databases. After reading the titles, abstracts, and applying inclusion and exclusion criteria, 23 clinical trials testing active cutaneous warming systems in the intraoperative period were included in this study. Primary studies were excluded due to the following reasons: written in a language other than English, Portuguese or Spanish $(n=8)$, sample of individuals younger than 18 years old or volunteers $(n=45)$, pre-warming was the intervention $(n=14)$, did not test cutaneous warming 
systems, passive warming systems (control group), induced hypothermia $(n=227)$, or appeared in more than one database $(n=30)$.

\section{Extracting data from primary studies}

Two authors (VBP and CMG) independently extracted data from the primary studies included in the review using a validated data collection instrument ${ }^{(8)}$. Data concerning the sample characteristics (i.e. number of subjects, type of anesthesia, type of surgery) and the intervention(s) being tested (i.e. circulating water mattress versus forced-air warming system) were recorded for each study selected along with their respective results and conclusions.

\section{Synthesis of available evidence}

The Jadad score $^{(9)}$ was used to evaluate the methodological quality of the randomized controlled clinical trials. Each clinical trial was evaluated in relation to its quality of randomization, whether it was double blind, and loss and withdrawals of the participants. The maximum score a clinical trial could obtain is 5 . The synthesis of evidence is descriptive to facilitate understanding each primary study included in the review.

\section{Results}

The 23 clinical trials included in this systematic review compared different active cutaneous warming systems with the forced-air warming system. The clinical trials were divided into eight categories according to the intervention being tested (Figure 2).

\section{Comparison between the radiant warming system and the forced-air warming system}

Four clinical trials comparing the radiant system with the forced-air warming system were included in this review ${ }^{(10-13)}$. We verified that the forced-air warming system was more effective in keeping body temperature compared with the radiant system in two studies(11-12); no statistically significant differences were observed between the groups investigated in the other two studies $^{(10,13)}$. The four clinical trials obtained a score of 3 on the Jadad scale, that is, they presented moderate quality.

\section{Comparison between the circulating water garment system and forced-air warming system}

The circulating water garment system was tested in six studies(14-19). This system was more effective in keeping body temperature in long procedures when compared to the forced-air warming system (statistically significant differences were observed among the studied groups). Two clinical trials obtained a Jadad score of 2 (low quality) (14,16) $^{2}$ and four obtained a 3 (moderate quality) $)^{(15,17-19)}$.

\section{Comparison between circulating-water mattress and the forced-air warming system}

Circulating-water mattress was compared with the forced-air warming system in four clinical trials(20-23). In one of the studies, a group using circulating-water mattress was compared with a group of patients using this system together with the forced-air warming system(23). The differences in temperature were statistically significant from the third hour of measurement, showing that the use of circulating-water mattress together with the forced-air warming system was more effective. The other three studies(20-22) reported that the forced-air warming system was better at preventing hypothermia (abdominal surgeries and general anesthetics). Three of the four clinical trials presented a Jadad score of 3 (moderate) $^{(20-22)}$ and one scored a 2 (low quality) ${ }^{(23)}$.

\section{Comparison between the electric heating pad and the forced-air warming system}

The electric heating pad was tested in two clinical trials(24-25). The electric system was as efficient as the forced-air warming system in maintaining patient body temperature in the study in which patients received epidural anesthesia(24). In the clinical trial(25) in which patients received general anesthesia, the electric heating pad was less efficient than the forced-air warming system. Both clinical trials scored 2 (low quality) on the Jadad scale.

\section{Comparison between the carbon-fiber resistive- warming system and the forced-air warming system}

The authors of five primary studies compared the carbon-fiber resistive-warming system with the forced-air warming system and the results indicate the systems are comparably effective in maintaining body temperature in the intraoperative period ${ }^{(18,20-21,26-27)}$. No statistically significant differences were found between groups in four of the studies(20-21,26-27); one of them reports statistically significant differences between the two tested systems ${ }^{(18)}$. In regard to the studies' methodological quality, three clinical trials scored 3 (moderate) $)^{(18,20-21)}$ on the Jadad scale and two scored 2 (low) (26-27). 
Comparison between energy transfer pads and the forced-air warming system

Energy transfer pads were tested in a clinical trial and they were more effective in maintaining patient normothermia when compared to the forced-air warming system. The study's sample however was small and the score obtained on the Jadad scale was $2^{(28)}$.

\section{Comparison between the warm water and pulsating negative pressure and the forced-air warming system}

Two clinical trials investigated the warm water and pulsating negative pressure. This new system has a device in the form of a clear cylinder, in which heated water circulates around a specific vascularized part of the body, such as the upper limbs(29-30).

The results obtained by the clinical trials were contradictory. One of the studies(29) reports the new device is more effective compared to the forced-air warming system in maintaining normothermia while the other study does not report statistically significant differences between the tested systems ${ }^{(30)}$. The two studies scored three in the Jadad scale. Given a lack of conclusive results coupled with the fact that the sample size of both trials is small, further studies are needed to test the new system.

\section{Comparison among types of the forced-air warming system}

Two studies compared types of forced-air warming system. One of the studies compared different disposable devices (disposable device for the upper limbs versus disposable device for the lower limbs) $)^{(31)}$. One trial tested the system with disposable devices for the upper limbs and trunk, while the equipment and devices were of different brands ${ }^{(32)}$. The results of both studies suggest that the forced-air warming system reduces hypothermia, though no statistically significant difference was observed. Both studies obtained a 3 on the Jadad scale.

\begin{tabular}{|c|c|c|c|c|}
\hline \multicolumn{5}{|c|}{ Radiant warming system (RW) x Forced-air warming system (FWS) } \\
\hline Study & $\mathbf{N}$ & Type of surgery & Type of anesthesia & Results \\
\hline Kadam et al. ${ }^{(13)}$ & $\mathrm{I}=14 \mathrm{C}=15$ & Laparoscopic cholecystectomy & General & $\mathrm{RW}=\mathrm{FWS}{ }^{*}$ \\
\hline Torrie et al. ${ }^{(12)}$ & $\mathrm{I}=28 \mathrm{C}=32$ & Transurethral resection of the prostate & Spinal anesthesia & $\mathrm{RW}<\mathrm{FWS}^{\dagger}$ \\
\hline Lee et al. ${ }^{(11)}$ & $I=29 \mathrm{C}=30$ & Surgeries longer than two hours & General & $\mathrm{RW}<\mathrm{FWS}^{\dagger}$ \\
\hline Wong et al. ${ }^{(10)}$ & $\mathrm{I}=21 \mathrm{C}=21$ & Laparoscopic cholecystectomy & General & $\mathrm{RW}=\mathrm{FWS}^{*}$ \\
\hline \multicolumn{5}{|c|}{ Circulating water garment system (CWG) $x$ Forced-air warming system (FWS) } \\
\hline Study & $\mathbf{N}$ & Type of surgery & Type of anesthesia & Results \\
\hline Zangrillo et al. ${ }^{(19)}$ & $\mathrm{I}=15 \mathrm{C}=16$ & Off-pump coronary artery bypass graft surgery & General & $\mathrm{CWS}>\mathrm{FWS}^{\dagger}$ \\
\hline Hofer et al. ${ }^{(18)}$ & $\mathrm{I}=30 \mathrm{C}=29$ & Off-pump coronary artery bypass graft surgery & General & CWS $>\mathrm{FWS}^{\dagger}$ \\
\hline Nesher et al. ${ }^{(17)}$ & $\mathrm{I}=45 \mathrm{C}=45$ & Off-pump coronary artery bypass graft surgery & General & CWS $>\mathrm{FWS}^{\dagger}$ \\
\hline Nesher et al. ${ }^{(16)}$ & $\mathrm{I}=40 \mathrm{C}=20$ & Off-pump coronary artery bypass graft surgery & General & $\mathrm{CWS}>\mathrm{FWS}^{\dagger}$ \\
\hline Janicki et al. ${ }^{(15)}$ & $\mathrm{I}=12 \mathrm{C}=12$ & Liver transplantation & General & $\mathrm{CWS}>\mathrm{FWS}^{\dagger}$ \\
\hline Janicki et al. ${ }^{(14)}$ & $\mathrm{I}=25 \mathrm{C}=28$ & Open abdominal surgery & General & $\mathrm{CWS}>\mathrm{FWS}^{\dagger}$ \\
\hline \multicolumn{5}{|c|}{ Circulating-water Mattress (CM) x Forced-air warming system (FWS) } \\
\hline Study & $\mathbf{N}$ & Type of surgery & Type of anesthesia & Results \\
\hline Pagnocca et al. ${ }^{(23)}$ & $\mathrm{I}=24 \mathrm{C}=19$ & Xifo-pubic laparotomy & General & $\mathrm{CM}<\mathrm{FWS}+\mathrm{CM}^{+}$ \\
\hline Ihn et al..$^{(22)}$ & $\begin{array}{c}I=30 \\
C_{A}=30 C_{B}=30\end{array}$ & Total abdominal hysterectomy & General & 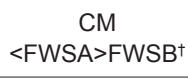 \\
\hline Negishi et al. ${ }^{(21)}$ & $I=8 \mathrm{C}=8$ & Open abdominal surgery & General & $\mathrm{CM}<\mathrm{FWS}^{\dagger}$ \\
\hline Matsuzaki et al. ${ }^{(20)}$ & $I=8 C=8$ & Laparoscopic cholecystectomy & General & $\mathrm{CM}<\mathrm{FWS}^{\dagger}$ \\
\hline \multicolumn{5}{|c|}{ Electric heating pads (EHP) x Forced-air warming system (FWS) } \\
\hline Study & $\mathbf{N}$ & Type of surgery & Type of anesthesia & Results \\
\hline Leung et al. ${ }^{(25)}$ & $\mathrm{I}=30 \mathrm{C}=30$ & Laparotomy & General & $\mathrm{EHP}<\mathrm{FWS}^{\dagger}$ \\
\hline $\mathrm{Ng}$ et al. ${ }^{(24)}$ & $I=30 C=30$ & Total knee replacement & Epidural & $\mathrm{EHP}=\mathrm{FWS}^{*}$ \\
\hline
\end{tabular}

(The Figure 2 continue in the next page...) 
(continuation)

\begin{tabular}{|c|c|c|c|c|}
\hline \multicolumn{5}{|c|}{ Carbon-fiber resistive-warming system (CF) x Forced-air warming system (FWS) } \\
\hline Study & $\mathbf{N}$ & Type of surgery & Type of anesthesia & Results \\
\hline Brandt et al. ${ }^{(27)}$ & $\mathrm{I}=40 \mathrm{C}=40$ & Orthopedic surgery & General or mixed & $\mathrm{CF}=\mathrm{FWS}{ }^{*}$ \\
\hline Fanelli et al. ${ }^{(26)}$ & $\mathrm{I}=28 \mathrm{C}=28$ & Total hip replacement & Spinal anesthesia & $\mathrm{CF}=\mathrm{FWS}^{*}$ \\
\hline Hofer et al. (18) & $\mathrm{I}=30 \mathrm{C}=30$ & Off-pump coronary artery bypass graft surgery & General & $\mathrm{CF}>\mathrm{FWS}^{\dagger}$ \\
\hline Matsuzaki et al. ${ }^{(20)}$ & $\mathrm{I}=8 \mathrm{C}=8$ & Laparoscopic cholecystectomy & General & $\mathrm{CF}=\mathrm{FWS}^{*}$ \\
\hline Negishi et al. ${ }^{(21)}$ & $\mathrm{I}=8 \mathrm{C}=8$ & Open abdominal surgery & General & $\mathrm{CF}=\mathrm{FWS}^{*}$ \\
\hline \multicolumn{5}{|c|}{ Energy transfer pads (ETP) x Forced-air warming system (FWS) } \\
\hline Study & $\mathbf{N}$ & Type of surgery & Type of anesthesia & Results \\
\hline Grocott et al. ${ }^{(28)}$ & $\mathrm{I}=14 \mathrm{C}=15$ & Off-pump cardiac surgery & General & $\mathrm{ETP}>\mathrm{FWS}^{+}$ \\
\hline \multicolumn{5}{|c|}{ Warm water and pulsating negative pressure (NPP) x Forced-air warming system (FWS) } \\
\hline Study & $\mathbf{N}$ & Type of surgery & Type of anesthesia & Results \\
\hline Trentman et al..$^{(30)}$ & $\mathrm{I}=25 \mathrm{C}=21$ & Total knee arthroplasty & General & $\mathrm{NPP}=\mathrm{FWS}^{*}$ \\
\hline Rein et al. ${ }^{(29)}$ & $\mathrm{I}=10 \mathrm{C}=10$ & Laparotomy for gastric surgery & General & $\mathrm{NPP}>\mathrm{FWS}^{\dagger}$ \\
\hline \multicolumn{5}{|c|}{ Forced-air warming system x Forced-air warming system (FWS) } \\
\hline Study & $\mathbf{N}$ & Type of surgery & Type of anesthesia & Results \\
\hline Wagner et al. ${ }^{(32)}$ & $\mathrm{I}=102 \mathrm{C}=94$ & Abdominal or orthopedic surgery & General & $\mathrm{FWSBH}=\mathrm{FWS}^{*}$ \\
\hline Motamed et al. ${ }^{(31)}$ & $I=13 C=13$ & Abdominal surgery & General & FWSUB $=F W S L B^{*}$ \\
\hline
\end{tabular}

*no statistically significant differences were found; ${ }^{+}$statistically significant; I=Intervention group; C=Control group; FWSBH=Forced-air warming system of another brand; FWSUB=Forced-air warming system with disposable component on the upper limbs; FWSLB=Forced-air warming system with disposable component on the lower limbs.

Figure 2 - Distribution of clinical trials included in the systematic review according to the tested active warming systems

\section{Discussion}

The forced-air warming system is effective in preventing hypothermia in surgical patients. It may, however, be insufficient to keep normothermia in some patients, such as elderly or severely ill individuals, or during certain procedures (i.e. liver transplantation or cardiac surgery) ${ }^{(1,5)}$.

The need for technologies capable of warming limited skin areas with optimal effectiveness coupled with difficulty maintaining normothermia in patients during the perioperative period has encouraged the development of new active cutaneous warming systems, among them, the circulating water garment system. This system has disposable devices that involve the patient's trunk and limbs and transfers a great amount of heat. Water has greater ability to transfer heat compared with air(33). The authors of a recent meta-analysis concluded that the circulating water garment system is more effective than the forced-air warming system in maintaining patient normothermia(34).

Energy transfer pads also have a unit generating heated water that circulates through hoses to disposable devices, which is similar to that used in the circulating water garment system. The devices of the latter, however, are adhesive, flexible hydrophilic gel, and can cover the patient's abdomen, back, and thighs ${ }^{(5,35)}$.
A study was conducted with seven male volunteers randomly allocated into three groups. The following systems were tested: circulating water garment system, energy transfer pads, and the forced-air warming system. The results indicate that the energy transfer pads were $25 \%$ faster than the circulating water garment system in recovering the individual temperature, and twice as fast as the forced-air warming system ${ }^{(36)}$.

Only one clinical trial(28) included in this review tested the energy transfer pads. Even though we did find, during the search for primary studies, another study ${ }^{(37)}$ testing this system, it was not a randomized controlled trial and had to be excluded, though its results also suggest that energy pads are more effective than the forced-air warming system. Therefore, further research testing this system is needed.

The carbon-fiber resistive-warming system was tested in five primary studies included in this review. Its components are not disposable and can be placed in different segments of the patient's body. The components are made with resistant and washable material and can be either sterilized or disinfected ${ }^{(18)}$.

A systematic review included 14 controlled randomized clinical trials comparing passive systems (i.e. cotton sheet) with the active cutaneous warming 
systems and its results indicate that the forced-air warming system and the carbon-fiber resistive-warming system are comparably effective in maintaining patient normothermia during the intraoperative period(38). The advantage in using systems that employ carbonfiber technology is related to reduced costs and lower environmental impact in terms of the waste generated, since its components are not disposable.

The radiant warming device is designed to increase body temperature through the irradiation of heat in a specific body area, usually one rich in arteriovenous anastomoses, such as the face or palms of the hands. This system also minimizes costs since it does not require disposable devices ${ }^{(10-12)}$ and its effectiveness should be further investigated since there is evidence that the forced-air warming system is more effective in maintaining normotherapy ${ }^{(11-12)}$.

Preventing hypothermia in patients during the intraoperative period can prevent complications associated with such an event, reduce hospital costs, improve the patients' thermal comfort and, consequently, their satisfaction(39). This systematic review supports the development of institutional policies intended to prevent this event. However, given the costs related to the acquisition of the investigated systems, each health facility should adopt systems that at least allow reducing hypothermia in patients during the perioperative period.

\section{Conclusion}

The implementation of measures to maintain patient normothermia in the intraoperative period is crucial to improving the quality of care provided to surgical patients. We conclude, based on this systematic review, that there is evidence indicating that the circulating water garment system is more effective in maintaining the temperature of patients in the intraoperative period. The forced-air warming system and the system employing carbon-fiber technology are comparably effective. However, we note that the highest Jadad score obtained by the studies was 3 , which indicates moderate methodological quality. Therefore, one needs to be cautious in interpreting the results reported by the clinical trials included in this systematic review.

Given the new technologies employed in active cutaneous systems, further studies are required to test systems that appear to be more efficient when compared to the forced-air warming system, such as energy transfer pads and those systems seldom investigated so far.
We also note the need to conduct studies addressing the costs involved in the implementation of active cutaneous warming systems in the perioperative to support the decision-making process concerning the acquisition of new equipment in health services.

\section{References}

1. Association of perioperative Registered Nurses. Recommended practices for the prevention of unplanned perioperative hypothermia. In: Association of perioperative Registered Nurses. Perioperative standards and recommended practices. Denver (USA): Association of periopertive Registered Nurses; 2009. p. 491-504.

2. Biazzotto $C B$, Brudniewski $M$, Schimidt AP; JúniorAuler JOC. Hipotermia no período peri-operatório. Rev Bras Anestesiol. 2006;56(1):89-106.

3. Scott EM, Buckland R. A systematic review of intraoperative warming to prevent postoperative complications. AORN J. 2006;83(5):1090-113.

4. Kumar S, Wong PF, Melling AC, Leaper DJ. Effects of perioperative hypothermia and warming in surgical practice. Int Wound J. 2005;2(3):193-204.

5.Kurz A. Thermal care in the perioperative period. Best Pract Res Clin Anaesthesiol. 2008;22(1):39-62.

6. Galvão CM, Sawada NO, Trevizan MA. Revisão sistemática: recurso que proporciona a incorporação das evidências na prática da enfermagem. Rev. Latino-Am. Enfermagem. 2004;12(3):549-56.

7. Higgins JPT, Green S. Cochrane handbook for systematic reviews of interventions. Version 4.2.6 [atualização set 2006] [Internet] UK: The Cochrane Collaboration; 2006 Sep [acesso 13 fev 2008]. Disponível em: http://www. cochrane.org/resources/handbook/index.htm

8. Ursi ES. Prevenção de lesão de pele no perioperatório: revisão integrativa da literatura. [dissertação de mestrado]. Ribeirão Preto (SP): Escola de Enfermagem de Ribeirão Preto da Universidade de São Paulo; 2005. 128 p.

9. Jadad AR, Moore RA, Caroll D, Jenkinson C, Reynolds DJM, Gavaghan DJ, et al. Assessing the quality of reports of randomized clinical trials: is blinding necessary? Controlled Clin Trials. 1996;17(1):1-12.

10. Wong A, Walker S, Bradley M. Comparison of a radiant patient warming device with forced air warming. Anaesth Intensive Care. 2004;32(1):93-9.

11. Lee L, Leslie K, Kayak E, Myles PS. Intraoperative patient warming using radiant warming or forced air warming during long operations. Anaesth Intensive Care. 2004;32(3):358-61. 
12. Torrie JJ, Yip P, Robinson E. Comparison of forced air warming and radiant heating during transurethral prostatic resection under spinal anaesthesia. Anaesth Intensive Care. 2005;33(6):733-8.

13. Kadam VR, Moyes D, Moran JL. Relative efficiency of two warming devices during laparoscopic cholecystectomy. Anaesth Intensive Care. 2009;37(3):464-8.

14. Janicki PK, Higgins MS, Janssen J, Johnson RF, Beattie C. Comparison of two different temperature maintenance strategies during open abdominal surgery. Anesthesiology. 2001;95(4):868-74.

15. Janicki PK, Stoica C, Chapman WC, Wright JK, Walker G, Pai R, et al. Water warming garment versus forced air system in prevention of intraoperative hypothermia during liver transplantation: a randomized controlled trial. BMC Anaesthesiol. 2002;2(7):1-5.

16. Nesher N, Insler SR, Shenberg N, Bolotin G, Kramer $A$, Sharony $R$, et al. A new thermoregulation system for maintaining perioperative normothermia and attenuating myocardial injury in off-pump coronary artery bypass surgery. Heart Surg Forum. 2002;5(4):373-80.

17. Nesher N, Uretzky G, Insler S, Nataf P, Frolkis I, Pineaus $E_{\text {, et }}$ al. Thermo-wrap technology preserves normothermia better than routine thermal care in patients undergoing off-pump coronary artery bypass and is associated with lower immune response and lesser myocardial damage. J Thorac Cardiovas Surg. 2005;129(7):1371-8.

18. Hofer CK, Worn M, Tavakoli R, Sander L, Maloigne M, Klaghofer $R$, et al. Influence of body core temperature on blood loss and transfusion requirements during offpump coronary artery bypass grafting: a comparison of 3 warming systems. J Thorac Cardiovas Surg. $2005 ; 129(4): 838-43$.

19. Zangrillo A, Pappalardo F, Talo G, Corno C, Landoni G, Scandroglio AM, et al. Temperature management during off-pump coronary artery bypass graft surgery: a randomized clinical trial on the efficacy of a circulating water system versus a forced-air system. J Cardiothorac Vasc Anesth. 2006;20(6):788-92.

20. Matsuzaki Y, Matsukawa T, Ohki K, Yamamoto $Y$, Nakamura M, Oshibuchi T. Warming by resistive heating maintains perioperative normothermia as well as forced air heating. $\mathrm{Br}$ J Anaesth. 2003;90(5):689-91.

21. Negishi C, Hasegawa K, Mukai S, Nakagawa F, Ozaki M, Sessler DI. Resistive-heating and forced air warming are comparably effective. Anaesth Analg. 2003;96(6):1683-7.
22. Ihn $\mathrm{CH}$, Joo JD, Chung HS, Choi JW, Kim DW, Jeon YS, Kim YS, Choi WY. Comparison of three warming devices for the prevention of core hypothermia and posanesthesia shivering. J Int Med Res. 2008;36(5):923-31. 23. Pagnocca ML, Tai EJ, Dwan JL. Controle de temperatura em intervenção cirúrgica abdominal convencional: comparação entre os métodos de aquecimento por condução e condução associada à convecção. Rev Bras Anestesiol. 2009;59(1):56-65.

24. $\mathrm{Ng} \mathrm{V}$, Lai A, Ho V. Comparison of forced air warming and electric heating pad for maintenance of body temperature during total knee replacement. Anaesthesia. 2006;61(11):1100-4.

25. Leung KK, Lai A, Wu A. A randomized controlled trial of the electric heating pad vs forced air warming for preventing hypothermia during laparotomy. Anaesthesia. 2007;62(6):605-8.

26. Fanelli A, Danelli G, Ghisis D, Ortu A, Moschini E, Fanelli $G$. The efficacy of resistive heating under-patient blanket versus a forced-air warming system: a randomized controlled trial. Anesth Analg. 2009;108(1):199-201.

27.Brandt S, Oguz R, Hüttner H, Waglechner G, Chiari $A$, Greif $R$, et al. Resistive-polymer versus forced-air warming: comparable efficacy in orthopedic patients. Anesth Analg. 2010;110(3):834-8.

28. Grocott HP, Mathew JP, Carver EH, Phillips-Bute B, Landolfo KP, Newman MF. A randomized controlled trial of the Artic Sun temperature management sytem versus conventional methods for preventing hypothermia during off-pump cardiac surgery. Anesth Analg. 2001;98(2):298-302.

29. Rein EB, Filtvedt M, Walloe L, Raeder JC. Hypothermia during laparotomy can be prevented by locally applied warm water and pulsating negative pressure. $\mathrm{Br}]$ Anaesth. 2007;98(3):331-6.

30. Trentman $T L$, Weinmeister KP, Hentz JG Laney MB, Simula DV. Randomized non-inferiority Trial of the vitalHEAT temperature management system vs the Bair Hugger warmer during total knee arthroplasty. Can J Anesth. 2009;56(12):914-20.

31. Motamed C, Labaille T, Léon O, Panzani JP, Duvaldestin $\mathrm{PH}$, Benhamou D. Core and thenar skin temperature variation during prolonged abdominal surgery: comparison of two sites of active forced air warming. Acta Anaesthesiol Scand. 2000;44(3):249-54. 
32. Wagner K, Swanson E, Raymond CJ, Smith CE. Comparison of two convective warming systems during major abdominal and orthopedic surgery. Can J Anesth. 2008;55(6):358-63.

33. Taguchi A, Ratnaraj J, Kabon B, Sharma N, Lenhardt R, Sessler DI, et al. A Effects of a circulating-water garment and forced-air warming on body heat content and core temperature. Anaesthesiology. 2004;100(5):1058-64.

34. Galvão CM, Liang Y, Clark AM. Effectiveness of cutaneous warming systems on temperature control: meta-analysis. J Adv Nurs. 2010;66(7):1196-206.

35. Taguchi A, Kurz A. Thermal management of the patient: where does the patient lose and/or gain temperature? Current Opinion in Anaesthesiol. 2005;18(6):632-9.

36. Wadhwa A, Komatsu R, Orhan-Sungur M, Barnes $P$, In J, Sessler DI, et al. New circulating-water devices warm more quickly than forced air in volunteers. Anesth Analg. 2007;105(6):1681-7.

37. Stanley TO, Grocott HP, Phillips-Bute B, Mathew JP, Landolfo KP, Newman MF. Preliminary evaluation of the arctic Sun temperature controlling system during off pump coronary artery bypass surgery. Ann Thorac Surg. 2003;75(4):1140-4.

38. Galvão CM, Marck PB, Sawada NO, Clark A M. A systematic review of the effectiveness of cutaneous warming systems to prevent hypothermia. J Clin Nurs. 2009;18(5):627-36.

39. Poveda VB, Galvão CM, Santos, CB. Factors associated to the development of hypothermia in the intraoperative period. Rev. Latino-Am. Enfermagem. 2009;17(2):228-33. 